\title{
sciforum
}

Conference Proceedings Paper

\section{Complex spatial and temporal influences of climatic drought time-scales on hydrological droughts in natural basins of U.S.}

\author{
Sergio Vicente-Serrano ${ }^{1, *}$, Marina Peña-Gallardo², Jamie Hannaford ${ }^{3}$, Jorge Lorenzo-Lacruz ${ }^{4}$, \\ Mark Svoboda ${ }^{5}$, Steven Quiring ${ }^{6}$, Fernando Dominguez-Castro ${ }^{7}$, Marco Maneta ${ }^{8}$, Miquel \\ Tomas-Burguera ${ }^{9}$, Ahmed El Kenawy ${ }^{10}$ \\ Published: 05/11/2017 \\ Academic Editor: José Marengo \\ 1 Instituto Pirenaico de Ecología, Spanish National Research Council (IPE-CSIC); svicen@ipe.csic.es \\ 2 Instituto Pirenaico de Ecología, Spanish National Research Council (IPE-CSIC); \\ marinapgallardo@ipe.csic.es \\ 3 Centre for Ecology and Hydrology (CEH); jaha@ceh.ac.uk \\ 4 Universidad de las Islas Baleares; j.lorenzo@uib.es \\ 5 National Drought Mitigation Centre, University of Nebraska-Lincoln; msvoboda2@unl.edu \\ 6 Ohio State University; quiring.10@osu.edu \\ 7 Instituto Pirenaico de Ecología, Spanish National Research Council (IPE-CSIC); f.dominguez@ipe.csic.es \\ 8 University of Montana; Marco.Maneta@mso.umt.edu \\ 9 Estación Experimental de Aula Dei, Spanish National Research Council (EEAD-CSIC); \\ mtomas@eead.csic.es \\ ${ }^{10}$ Instituto Pirenaico de Ecología, Spanish National Research Council (IPE-CSIC); kenawy@ipe.csic.es \\ * Correspondence: svicen@ipe.csic.es; Tel.: +34-976-369-393
}

\begin{abstract}
We have analysed the response of hydrological droughts to climatic droughts in different natural basins of United States of America. For this purpose we selected 289 complete series from an initial data set of 702 gauging stations, covering the period between 1940 and 2013. Drainage basins were obtained for each gauging station using a digital terrain model, and climate series (precipitation and the atmospheric evaporative demand) were obtained for each drainage series. A number of topographic, edaphic and remote sensing variables were quantified for each basin. A hydrological drought index (The Standardized Stream Flow Index-SSI) was obtained for each basin and the Standardized Precipitation Evapotranspiration Index (SPEI) was used as a metric of climatic drought severity. Relationship between different SPEI time scales and the SSI was quantified using Pearson's correlations and the general patterns of response of hydrological droughts to climatic droughts were identified using a principal component analysis. In general there is a response of SSI to short SPEI time-scales but strong seasonality in this response is also found. Coherent geographic patterns were obtained from the analysis and the factors that control the different responses were analysed by means of a predictive discriminant analysis. Independent analysis for three periods (1940-1964, 1965-1989 and 1989-2013) were also performed and showed not important changes in the response of the SSI to the SPEI in the past 65 years.
\end{abstract}

Keywords: hydrological drought, time scales, drought propagation. 
The 1st International Electronic Conference on Hydrological Cycle (CHyCle-2017), 12 - 16 November 2017; Sciforum Electronic Conference Series, Vol. 1, 2017

\section{Introduction}

The response of hydrological droughts to climate drought conditions is complex and it depends on a number of factors that include natural (e.g., lithology, topography, vegetation coverage) and anthropic (e.g., water regulation and use) [1,2]. Nevertheless, there are not previous studies that have analysed if the response of hydrological droughts is noticeably different among natural basins, which are characterizes by low human intervention. The analysis of natural basins would allow to determine the main environmental factors that affect the propagation of climate dry periods throughout the hydrological cycle. In this study we analyse the relationship between a hydrological drought index: the Standardised Streamflow Index (SSI) [3] and different time-scales of a climatic drought index. For this purpose we use a high density natural basisns streamflow dataset covering the conterminous US.

\section{Data}

We have used the USGS Hydro-Climatic Data Network 2009 (HCDN-2009), which contains monthly streamflow records from 702 gauging stations characterized by being located in natural catchments. From the original stations we selected those characterized by few data gaps and covering the period 1940-2013. Following this criterion, we selected 289 stations. The few existing data gaps were completed by a procedure in which a standardized regional series was created for each station using the most correlated series with each target series. While this procedure maintains the temporal variance of the original data, it provides a low biased estimation of the missing values. In order to avoid biases in the filling due to differences in the distribution parameters (mean and variance) between the candidate and the objective data series, a bias correction was performed on the candidate data.

Monthly gridded precipitation and temperature data was obtained We employed the PRISM (Parameter-elevation Relationships on Independent Slopes Model) gridded data set developed by the Oregon State University (http://www.prism.oregonstate.edu/) [4].

Different environmental variables were obtained from the NOAA-AVHRR NDVI dataset (https://www.star.nesdis.noaa.gov/smcd/emb/vci/VH/vh_browse.php). Finally, high resolution soil variables were obtained from the State Soil Geographic (STATSGO) Database for the contiguous United States (https://water.usgs.gov/GIS/metadata/usgswrd/XML/ussoils.xml\#stdorder).

\section{Methods}

1- to 48-month Standardized Precipitation Evapotranspiration Index (SPEI) time scales were used to quantify drought severity from mean series of precipitation and reference evapotranspiration (ETo) of each basin [5]. ETo was calculated according to the Hargreaves method [6] using maximum and minimum air temperatures and extraterrestrial solar radiation data calculated using latitude and Julian day. The influence of climatic droughts on the hydrological drought conditions was assessed using the Pearson correlation coefficient. The correlation was computed between the time series of the SPEI for all months of the year, using SPEI aggregation periods of 1- to 48-months (i.e. the month in question and then aggregating two to 48 months prior) and the series of the SSI for each basin independently. To summarize the high variability in the correlations computed between the SSI and SPEI, we performed a Principal Component Analysis (PCA) in S mode, in which each vector was the 12 (months) x 48 (time-scale) correlations (576 cases) obtained between SPEI and SSI in each basin. This approach enabled us to classify, at the broad scale, the patterns of response 
The 1st International Electronic Conference on Hydrological Cycle (CHyCle-2017), 12 - 16 November 2017;

Sciforum Electronic Conference Series, Vol. 1, 2017

recorded in individual counties, on the basis of the similarities of the obtained correlations. Finally we analysed possible differences in the patterns of response as a function of the climatology, vegetation coverage, basin and soil characteristics.

\section{Results}

Figure 1 shows the spatial distribution of the maximum correlation between SPEI time-scales and SSI for the independent monthly series and the series of all months. In general, there are strong positive and significant correlations in the majority of analysed basins.

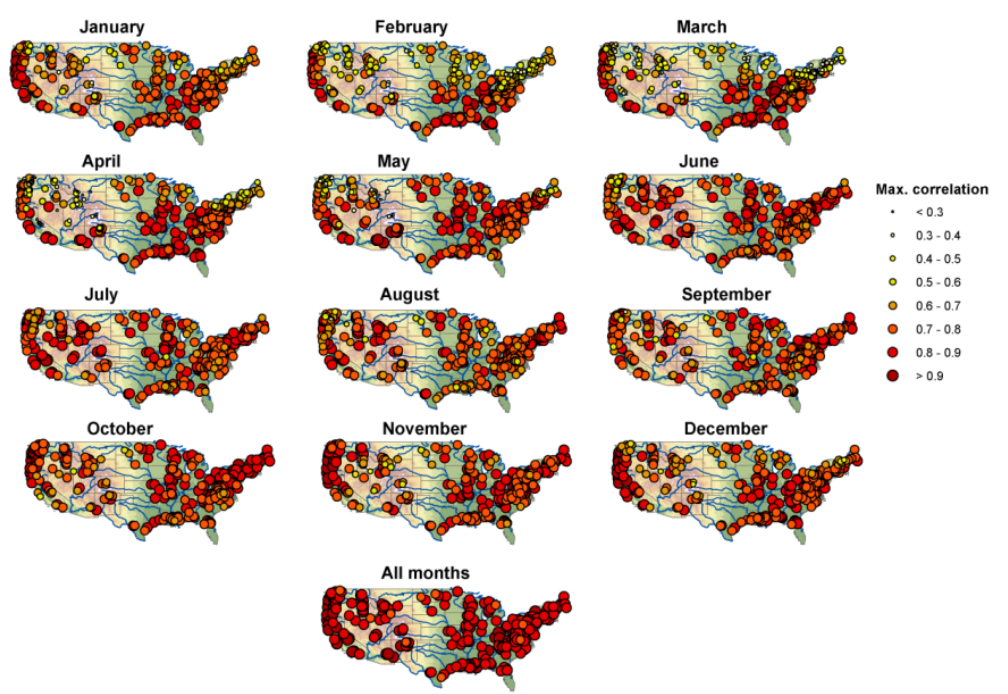

Figure 1. Spatial distribution of maximum correlation between SPEI time-scales and SSI from monthly series and the series of all months.

Nevertheless, there are important differences in the SPEI time scale at which maximum correlation is found (Figure 2) since the inner basins show response to longer SPEI time-scales than the stations of the West and East of the country.

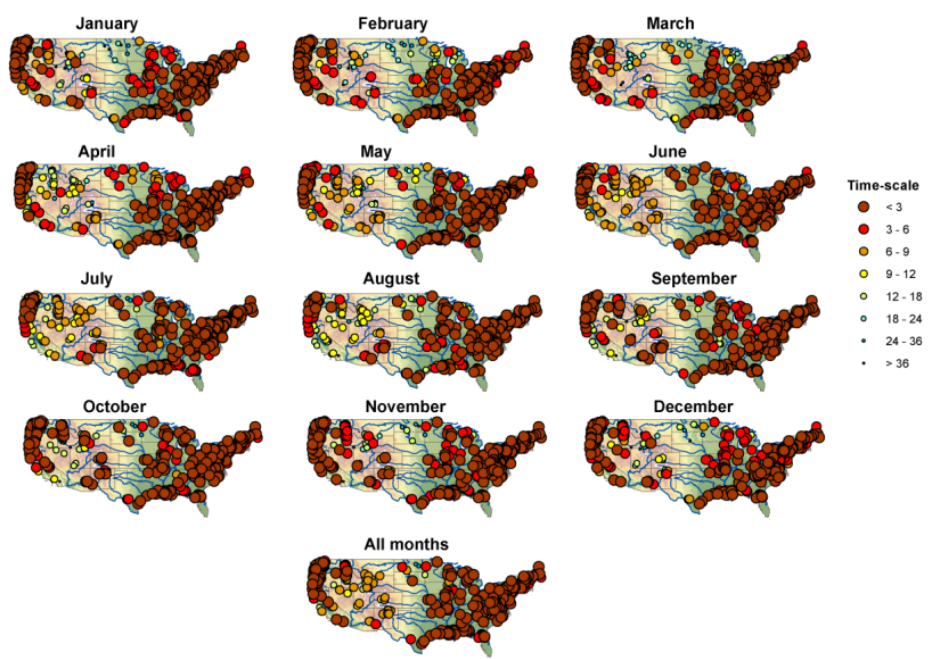

Figure 2. Spatial distribution of the SPEI time-scale at which maximum correlation between SPEI timescales and SSI is found (monthly series and the series of all months). 
The 1st International Electronic Conference on Hydrological Cycle (CHyCle-2017), 12 - 16 November 2017; Sciforum Electronic Conference Series, Vol. 1, 2017

Figure 3 shows principal component scores (left) and the Pc loadings to identify the main patterns of response of hydrological droughts to time scales of climatic droughts in the US. There are clear differences in the response with coherent geographical patterns. In general, there is a dominant of response to short SPEI time scales but with some exception (e.g., PC 4), which characterizes the behavior of the basins located in the Rocky Mountains.

Figure 4 represents different box-plots to illustrate the distribution of the different variables as a function of the PC groups of response of SPEI time scales to the SSI. The annual NDVI shows strong differences between groups, which means that components 3, 4 and 5 are characterised by less vegetation activity and coverage than components 2,3 and 7 . Also soil characteristics indicate some differences among components but the main differences are provided by the climatic variables since there are strong difference in the average precipitation and ETo among the obtained principal components.
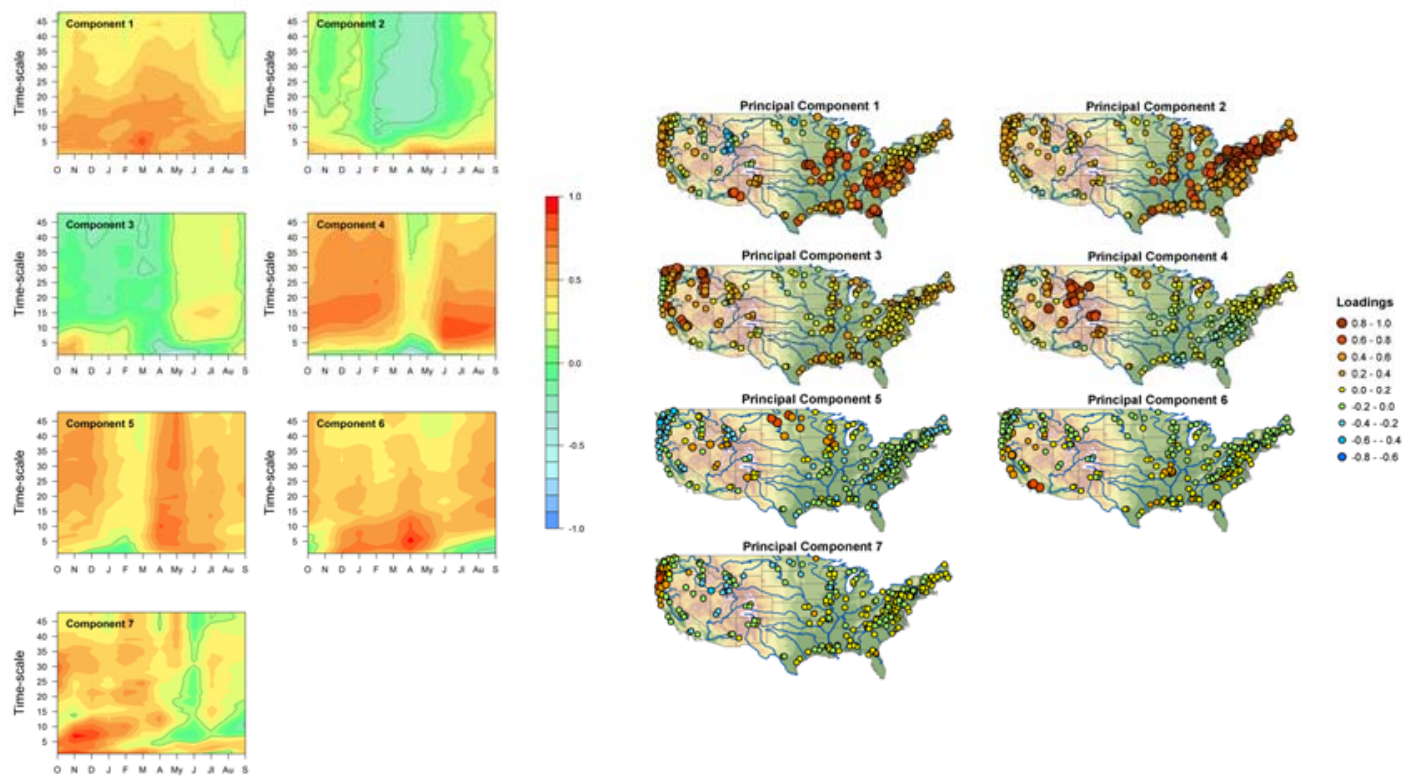

Figure 3. Left: Principal component scores obtained from correlations between SPEI time-scales and SSI (1940-2013). Rigth: Spatial distribution of the loadings of the extracted principal components from patterns of correlation between SPEI time-scales and the SSI

\section{Conclusions}

We have showed that the response of hydrological drought to climatic droughts can be extremely complex in the form of the climatic drought time scale that better controls the hydrological drought severity. This is expected in areas strongly modified and regulated basins, in which water management or dam operation rules may strongly change the behavior. Nevertheless, here we have showed that also in natural basins the response of the hydrological droughts to climate drought conditions can be strongly complex. We have found in US very different patterns of response of the SSI to the SPEI characterized by coherent geographic patterns and by different climatological and vegetation conditions. 
The 1st International Electronic Conference on Hydrological Cycle (CHyCle-2017), 12 - 16 November 2017; Sciforum Electronic Conference Series, Vol. 1, 2017

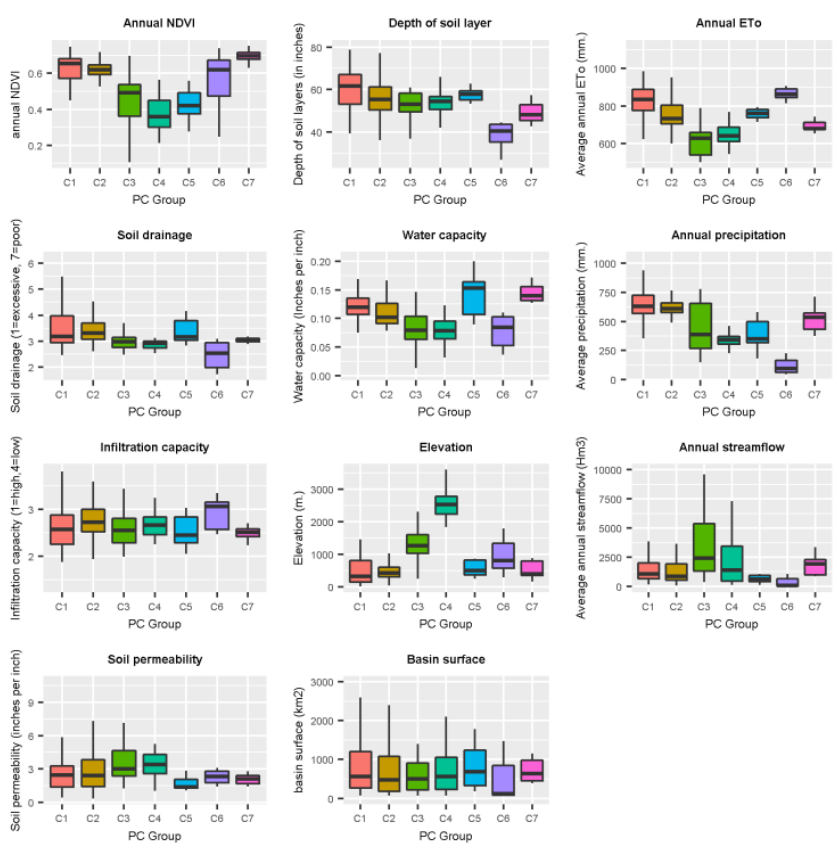

Figure 4. Box-plots showing different terrain and environmental variables corresponding to the seven components obtained from patterns of correlation between SPEI time-scales and the SSI.

Acknowledgments: This work was supported by the research project I-Link1001 (Validation of climate drought indices for multi-sectorial applications in North America and Europe under a global warming scenario) financed by CSIC, PCIN-2015-220 and CGL2014-52135-C03-01 financed by the Spanish Commission of Science and Technology and FEDER, IMDROFLOOD financed by the Water Works 2014 co-funded call of the European Commission and INDECIS, financed by the ERA-NET Cofund for Climate Services of the European Research Area for Climate Services. Marina Peña-Gallardo was granted by the Spanish Ministry of Economy and Competitiveness and Miquel Tomas-Burguera was supported by a doctoral grant by the Ministerio de Educación, Cultura y Deporte.

Author Contributions: All the authors contributed equally to the manuscript.

Conflicts of Interest: “The authors declare no conflict of interest."

\section{References}

1. Barker, L.J., Hannaford, J., Chiverton, A., Svensson, C. From meteorological to hydrological drought using standardised indicators. Hydrol. Earth Syst.Sci. Discuss. 2015, 12, 12827-12875.

2. Lorenzo-Lacruz, J., Vicente-Serrano, S.M., González-Hidalgo, J.C., López-Moreno, J.I., Cortesi, N. Hydrological drought response to meteorological drought at various time scales in the Iberian Peninsula. Climate Research. 2013, 58, 117-131SSI

3. Daly, C., Halbleib, M., Smith, J.I. Physiographically sensitive mapping of climatological temperature and precipitation across the conterminous United States. International Journal of Climatology, 2008, 28, 20312064. 
The 1st International Electronic Conference on Hydrological Cycle (CHyCle-2017), 12 - 16 November 2017; Sciforum Electronic Conference Series, Vol. 1, 2017

4. Vicente-Serrano, S.M., Beguería, Santiago, López-Moreno, J.I. A Multi-scalar drought index sensitive to global warming: the StandardizedPrecipitation Evapotranspiration Index - SPEI. J. Climate, 2010, 23, 16961718.

5. Hargreaves, G.L., Samani, Z.A. Reference crop evapotranspiration from temperature. Appl. Eng. Agric., $1985,1,96-99$.

(C) 2017 by the authors; licensee MDPI, Basel, Switzerland. This article is an open access article distributed under the terms and conditions of the Creative Commons by Attribution (CC-BY) license (http://creativecommons.org/licenses/by/4.0/). 